$\xi=$

\title{
Geoelectric evaluation of groundwater potential within sunshine garden estate, akure southwestern Nigeria
}

\author{
Rereloluwa Bello $^{1 *}$, Toluwaleke Ajayi ${ }^{1}$ \\ ${ }^{1}$ Department of Earth and Physical Sciences, Crawford University, Nigeria \\ *Corresponding author E-mail: bellorereloluwa@yahoo.com
}

\begin{abstract}
The Vertical Electrical Resistivity surveys in the Sunshine Garden Estate have contributed to a better understanding of the basement complex of Southwestern Nigeria. Nine (9) vertical electrical sounding (VES) using the Schlumberger electrode array were interpreted and the results shows three (3) subsurface geoelectric layers within the study area. These are the weathered layer, topsoil, fresh/fractured basement. Groundwater pockets such as fractured zones, valley fills/basement depressions, and weathered zones were delineated in the study area. Weathered/partially weathered layer and weathered basement/fractured basement were the two major aquifer mapped out and these aquifers are characterized by thick overburden, found within basement depressions. The groundwater potential of the study area was zoned into low, medium and high potentials. Zones where the overburden thickness (which constitutes the main aquifer unit) is greater than $13 \mathrm{~m}$ and of low clay composition (average resistivity value between $200-400 \Omega \mathrm{m}$ ) are considered zones of high groundwater potential. Area where the thickness of the aquifer ranges from $11-13 \mathrm{~m}$ with less clay composition are considered to have medium groundwater potential and the areas where the thickness of the aquifer is less than $11 \mathrm{~m}$ are considered to have a low groundwater. The VES station underlained by high and medium groundwater potential zones are envisaged to be viable for groundwater development within the area.
\end{abstract}

Keywords: Vertical Electrical Sounding; Basement; Weathered Layer; Groundwater Potential.

\section{Introduction}

The changes in electrical properties, thickness and lithological features of weathered bedrock materials usually make VES (vertical electrical sounding) data from basement complex terrain very difficult especially during interpretation. Protecting and Maintaining water supplies facilities and generating potential sources of clean and potable water are important as expansion and civilization of the society continues to develop. Water is very essential for life. It will always continue to be an important topic in both the scientific and political arenas for years to come [1].

Over the year, the application of geophysics for both mapping of groundwater resource and for evaluation of water quality has increased dramatically. The vertical Electrical Sounding (VES) has proved very effective in groundwater investigation studies because it delineates subsurface structures identifying potential aquiferous zone for groundwater accumulation [2][3]. The increase in population growth as a result of industrial and agricultural activities has led to increase in water demand within Akure and its environs. Inadequate supply of water is the major problem with Sunshine Estate as surface water, hand dug wells and borehole water can no longer serve its purpose of providing water supply. Hence, there is a need for adequate geophysical investigation of the area with the aim of evaluating groundwater potential zones of the study area.

This article focuses on the application of electrical resistivity method as a geophysical technique for groundwater studies. In cases where geological structure are not complicated, electrical resistivity methods can be used effectively and apparent resistivity can be estimated.Vertical Electrical Sounding(VES) is a non-invasive geophysical survey configuration that has become successful in the prospect for groundwater potential in the basement complex of Nigeria[4][5].

\section{Location of the study}

Oba-Ile is located at the outskirt of the Akure metropolis, southwestern Nigeria; it lies within the basement complex terrain of Nigeria. It is bounded between longitudes $07^{\circ} 15^{\prime} 30^{\prime \prime}$ and $7^{\circ} 16^{\prime} 80^{\prime \prime} \mathrm{N}$, and latitude $05^{\circ} 14^{\prime} 45^{\prime \prime}$ and $05^{\circ} 15^{\prime} 90^{\prime \prime} \mathrm{E}$. Fig 1 shows the map of Ondo State indicating the study area and (Fig 2) shows the layout of sunshine Estate Oba-Ile Akure. 


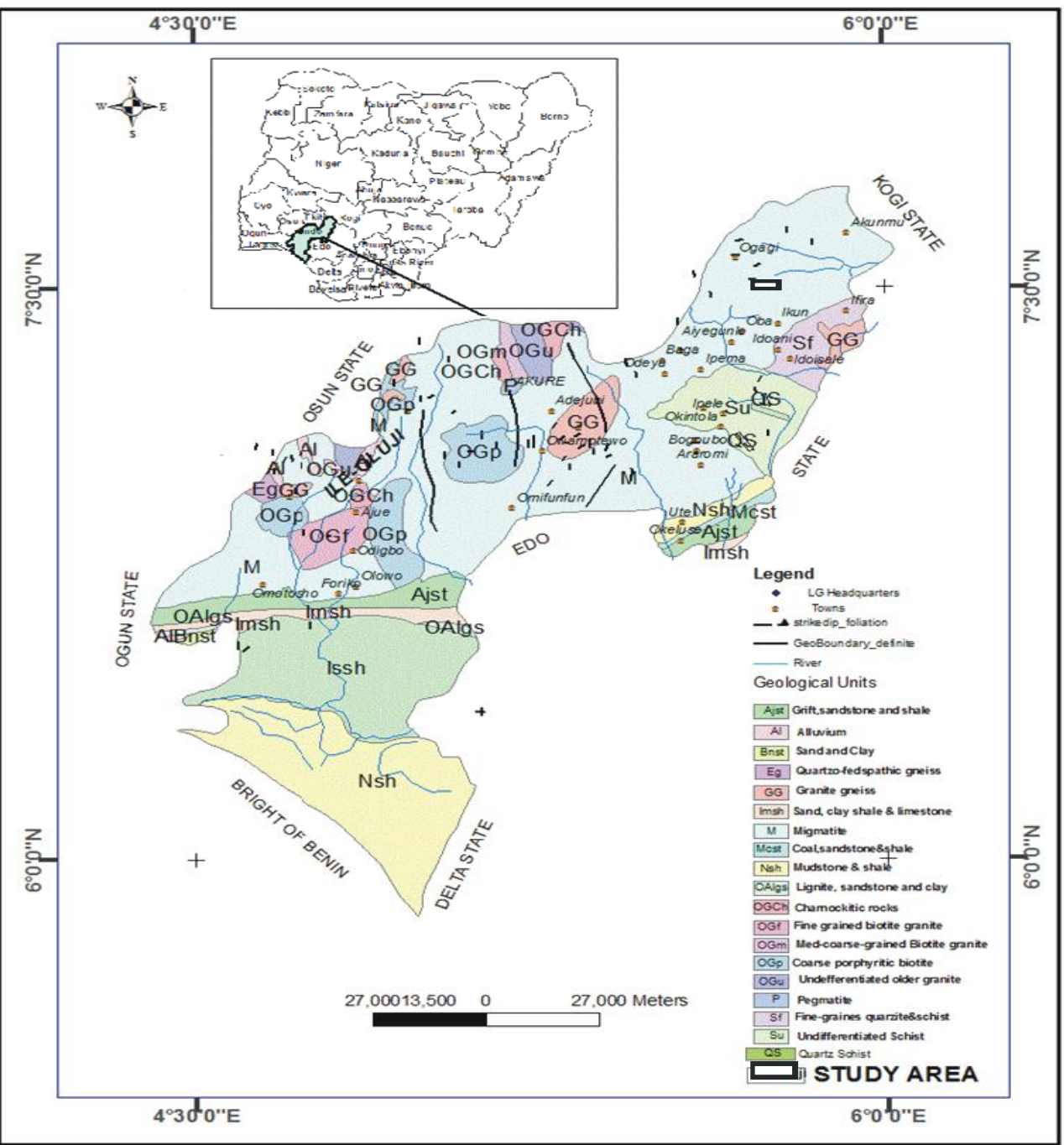

Fig. 1: Geological Map of Ondo State Showing the Study Area (Source: Modified after GSN).

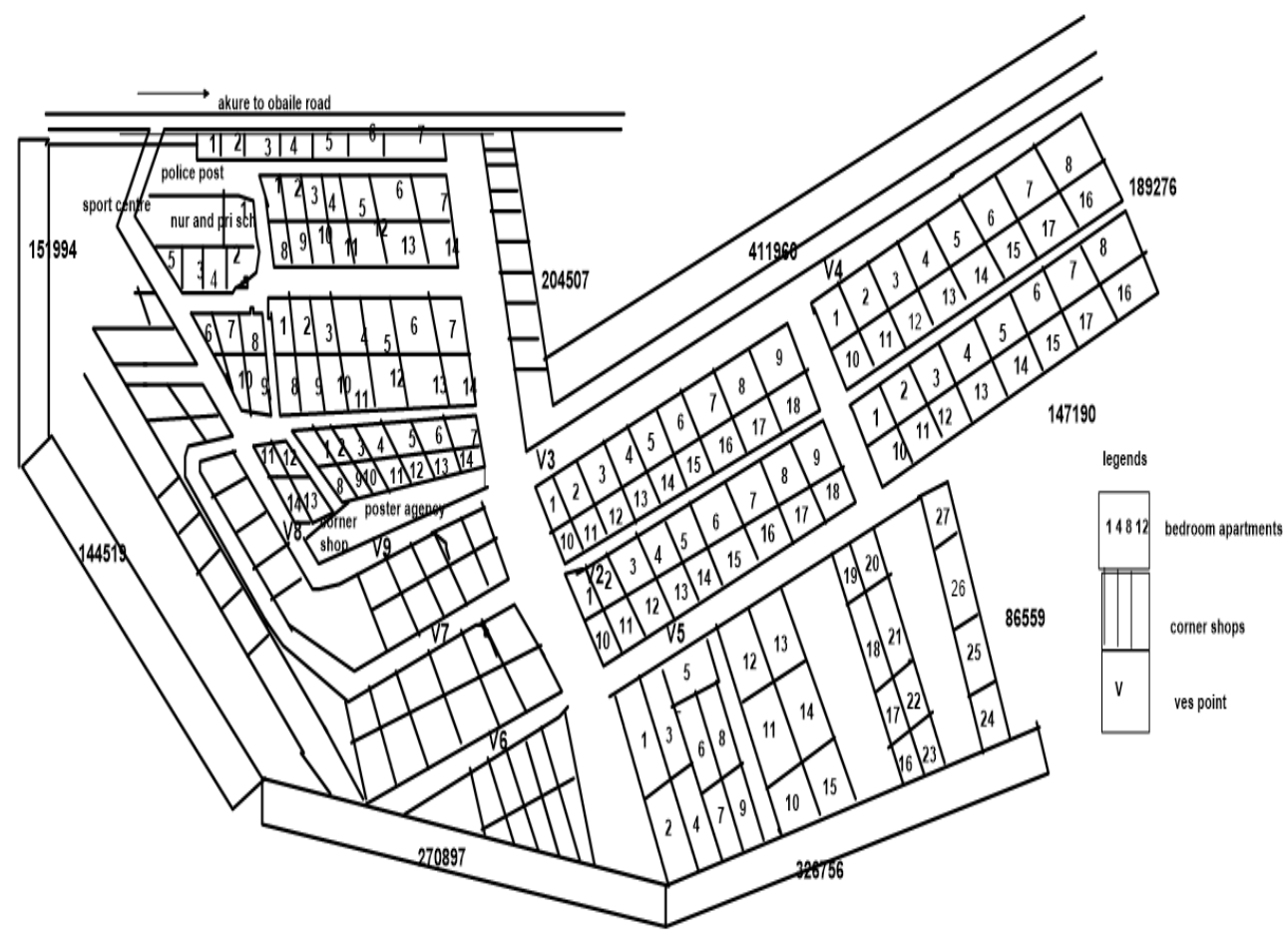

Fig. 2: Map Showing the Layout of Sunshine Garden Estate Oba-Ile Akure. 


\section{Geology of the study area}

The study area lies within the basement complex terrain, a south western Nigeria. It consists of early to late Proterozoic crystalline rocks of migmatites, quartzite and granites overlain by sequences of low grade porphyritic schist's. The basement complex covers about $50 \%$ of Nigeria and also extends to neighboring countries; Cameroon and Benin [6].

The dominant rock types include garnet-biotite-schist and Gneiss-biotite-garnet, quartz schist and quartzite, variably undifferentiated hornblende-biotite-gneiss with intercalated amphibole, all belonging to the hornblende biotite gneiss and gneiss complex which are part of the older granite suite.

\section{Methodology}

The geophysical technique used for this study is the Vertical Electrical Sounding (VES) techniques and Electrical resistivity method. The ABEM SAS-1000 Terrameter was the instrument used for acquiring the data. The Schlumberger electrode configuration survey array was used for the study and the electrode spacing $(\mathrm{AB} / 2)$ was varied from 1 to $65 \mathrm{~m}$. The expected depth of investigation was $(\mathrm{D})=0.125$ $\mathrm{L}$, where $\mathrm{L}=\mathrm{AB} / 2$, and $\mathrm{AB}$ is the current electrode separation. Datas were presented as sounding curves which is obtained by a plot of apparent resistivity against $\mathrm{AB} / 2$ on a bi-log paper. The resulting electrical resistances obtained were further multiplied by (k) which is the geometric factor for each electrode separation in order to obtain the apparent resistivity $(\rho=k R)$ in ohm-meter. The resulting models obtained from the calculations stated above were used for computer iteration in order to obtain the thickness and true resistivity of the layers. Comparism was made between the computer-generated curves and the corresponding field curves by using a computer program "Resist" version 1.0. The software was further used for both modeling and computer iteration.

\section{Results and discussion}

The result of the geophysical investigation which involves very low frequency electromagnetic method(VLF-EM) were presented as profiles and vertical electrical sounding (VES) results were presented as depth sounding curves and Geoelectric sections.

\subsection{Depth sounding curves}

The results of this study are presented as geoelectric sections, sounding curves, tables and maps. $\mathrm{H}$ and $\mathrm{KH}$ are the curve types identified in the study. The $\mathrm{H}$ curve type is the predominant curve type with a percentage frequency of $77.78 \%$ while the $\mathrm{KH}$ curve types have $22.2 \%$ of the total occurrence. It is possible to use this curve type to make hydrogeologic deductions [7]. The occurrence of the KH curve type suggest subsurface geoelectric configuration favoring groundwater potential. Table $1 \& 2$ shows the summary of the formation layer parameters and classification of sounding curves respectively.

Table 1: Summary of the Formation of Layer Parameters

\begin{tabular}{|c|c|c|c|c|c|c|c|c|}
\hline Location & $\begin{array}{c}\text { Layer } 1 \\
\rho 1(\Omega \mathrm{m})\end{array}$ & $\mathrm{h} 1 / \mathrm{m}$ & $\begin{array}{l}\text { Layer } 2 \\
\rho 2(\Omega \mathrm{m})\end{array}$ & $\mathrm{h} 2 / \mathrm{m}$ & $\begin{array}{l}\text { Layer } 3 \\
\rho 3(\Omega \mathrm{m})\end{array}$ & $\mathrm{h} 3 / \mathrm{m}$ & $\begin{array}{l}\text { Layer } 4 \\
\rho 4(\Omega \mathrm{m})\end{array}$ & $\mathrm{h} 4 / \mathrm{m}$ \\
\hline VES 1 & 258.7 & 3.6 & 72.1 & 4.1 & 656.3 & 8.8 & 553.9 & - \\
\hline VES 2 & 419.0 & 2.4 & 679.0 & 1.1 & 91.6 & 8.4 & 12207.8 & - \\
\hline VES 3 & 142.1 & 4.0 & 36.2 & 6.0 & 24640.3 & - & - & - \\
\hline VES 4 & 319.5 & 1.8 & 330.0 & 13.9 & 1588.9 & - & - & - \\
\hline VES 5 & 268.1 & 3.7 & 88.5 & 3.4 & 701.3 & - & - & - \\
\hline VES 6 & 181.7 & 2.7 & 97.2 & 3.9 & 832.9 & - & - & - \\
\hline VES 7 & 1566.5 & 1.8 & 106.8 & 14.1 & 4087.4 & - & - & - \\
\hline VES 8 & 103.8 & 2.7 & 25.3 & 4.9 & 1593.7 & - & - & - \\
\hline VES 9 & 288.9 & 3.1 & 71.3 & 9.5 & 2577.3 & - & - & - \\
\hline
\end{tabular}

Table 2: Classification of the Resistivity Sounding Curves

\begin{tabular}{lllc} 
& \multicolumn{4}{c}{ Table 2: Classification of the Resistivity Sounding Curves } \\
\hline Curve Types & Resistivity Model & Model Frequency & VES Location \\
\hline H & $\rho 1>\rho 2<\rho 3$ & 7 & 3456789 \\
KH & $\rho 1<\rho 2>\rho 3<\rho 4$ & 2 & 12 \\
Total & & 9 & $22.22 \%$ \\
\hline
\end{tabular}

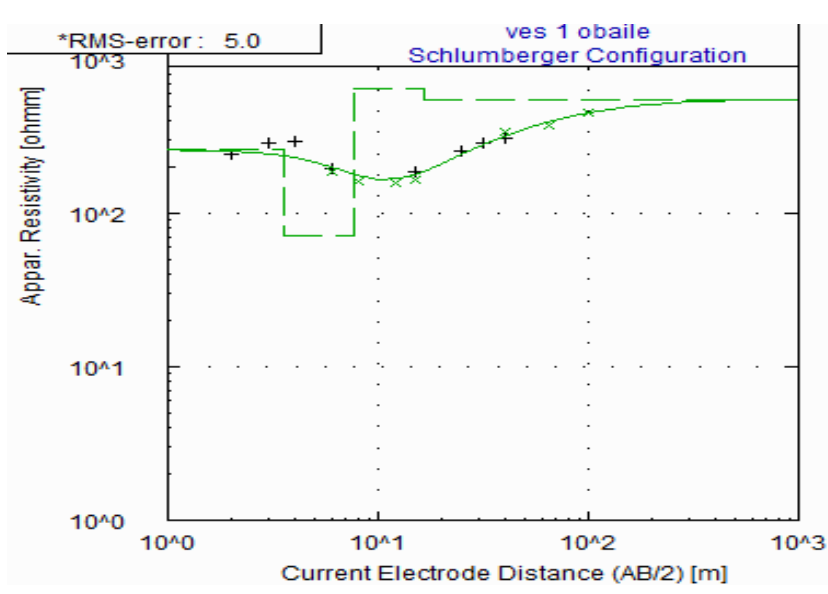

\begin{tabular}{|cccc} 
No & Res & Thick & Depth \\
\hline 1 & 258.7 & 3.6 & 3.6 \\
2 & 72.1 & 4.1 & 7.7 \\
3 & 656.3 & 8.8 & 16.4 \\
4 & 553.9 &.-- &.-- \\
* & \multicolumn{4}{c}{ RS on smoothed data }
\end{tabular}

Fig. 3: A Typical KH Type Curve. 


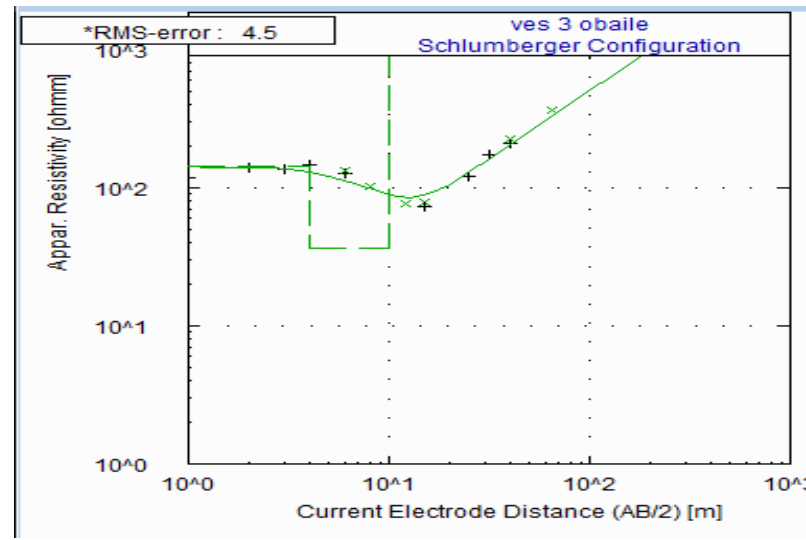

\begin{tabular}{|lccc|}
\hline No & Res & Thick & Depth \\
\hline 1 & 142.1 & 4.0 & 4.0 \\
2 & 36.2 & 6.0 & 10.0 \\
3 & 24640.3 &.-- &.-- \\
* RMS on smoothed data
\end{tabular}

Fig. 4: A Typical H Type.

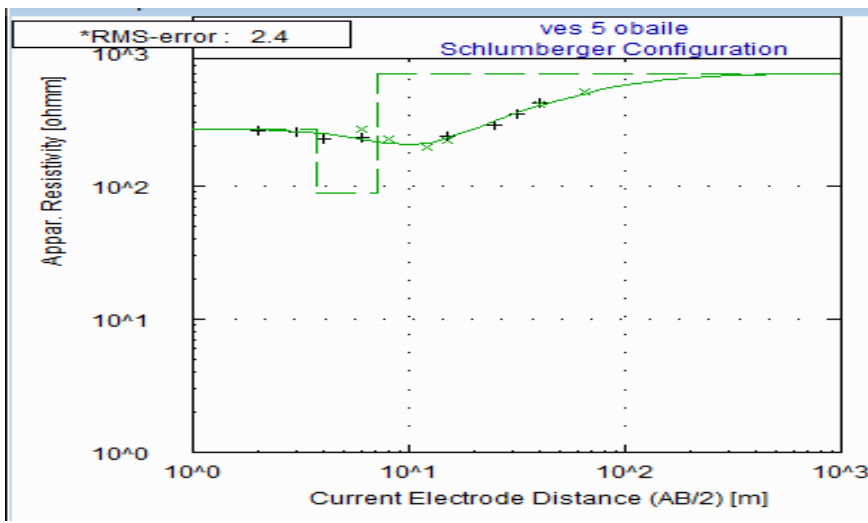

\begin{tabular}{|llll}
\hline No & Res & Thick & Depth \\
\hline 1 & 268.1 & 3.7 & 3.7 \\
2 & 88.5 & 3.4 & 7.1 \\
3 & 701.3 &.-- &.- \\
* RMS on smoothed data
\end{tabular}

Fig. 5: A Typical H Type Curve.

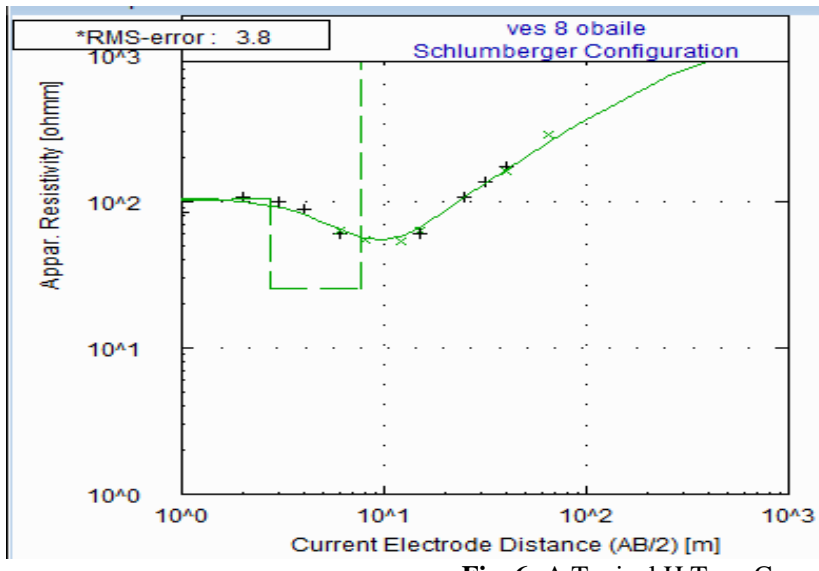

\begin{tabular}{|ccccc}
\hline No & Res & Thick & Depth \\
\hline 1 & 103.8 & 2.7 & 2.7 \\
2 & 25.3 & 4.9 & 7.6 \\
3 & 1593.7 &.-- &.-- \\
* RMS on smoothed data
\end{tabular}

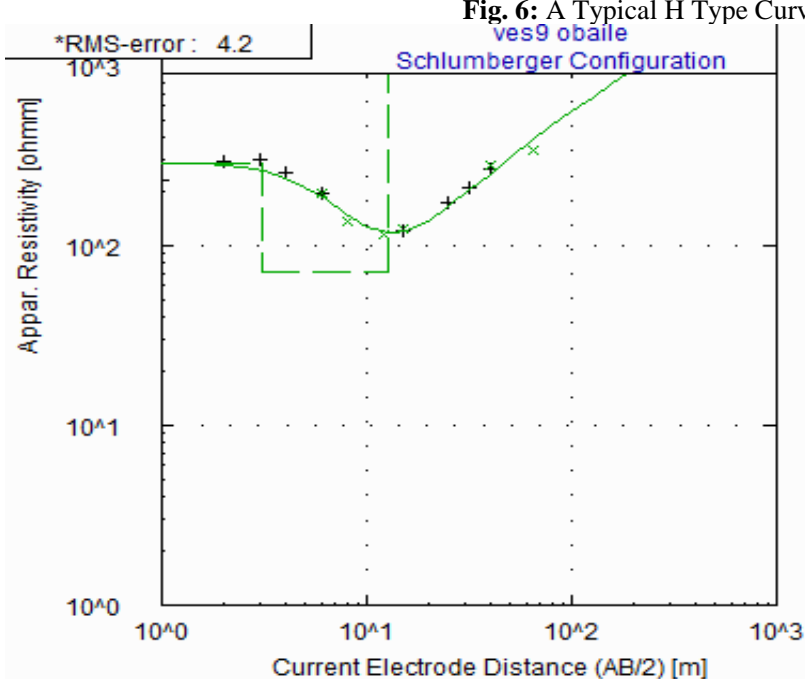

No Res Thick Depth

$\begin{array}{llll}1 & 288.9 & 3.1 & 3.1\end{array}$

$\begin{array}{llll}2 & 71.3 & 9.5 & 12.6\end{array}$

$32577.3 \ldots$

${ }^{\text {* }}$ RMS on smoothed data

Fig. 7: A Typical H Type Curve.

\subsection{Geoelectric sequence}


Figure 8 to 11 shows four (4) geoelectric sections along the W-E, N-S direction. The geoelectric section reveals the resistivity variation and layer thickness values within the depth covered in the study area at each VES station. Four subsurface geologic layers were observed in the geoelectric section which consists of weathered layer, topsoil, fractured and fresh basement. The topsoil is observed to be relatively thin and the thickness ranges between $1.8-4.0 \mathrm{~m}$ with its resistivity values ranging from $103.5-1566.5 \Omega \mathrm{m}$. This shows that the topsoil is dominated by sandy clay, clay, clayey sand bedrock leading to high resistivity value of the topsoil resistivity. The resistivity values of the

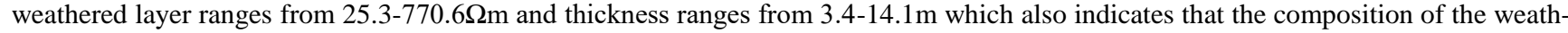
ered layer is sandy clay, clay, laterite and clayey sand. The last observable layer is of infinite thickness and it is underlain by fractured/fresh bedrock with thickness ranging from 3.4-14.1m and resistivity values ranging between $1000 \Omega \mathrm{m}$ to infinity. At most VES station in the study, it is infinitely resistive due to its crystalline nature. The geoelectric section further shows that the overburden layer is generally thin. The thin nature of the overburden of less than $11 \mathrm{~m}$ as seen in the geoelectric section makes the area less hydrogeological appeal except where saturated thickness of greater than $11 \mathrm{mis}$ observed.

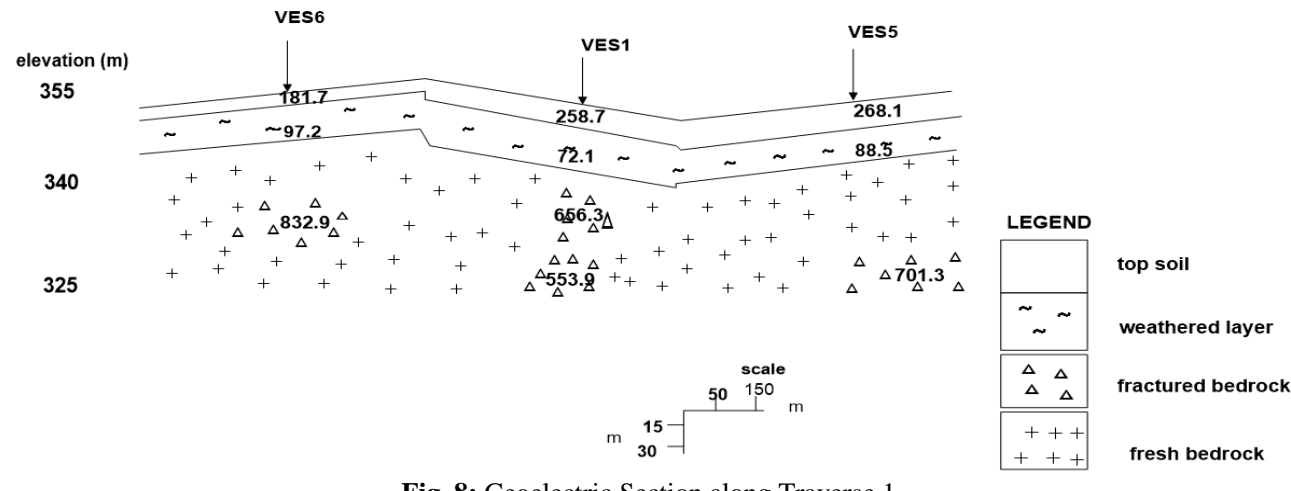

Fig. 8: Geoelectric Section along Traverse 1.

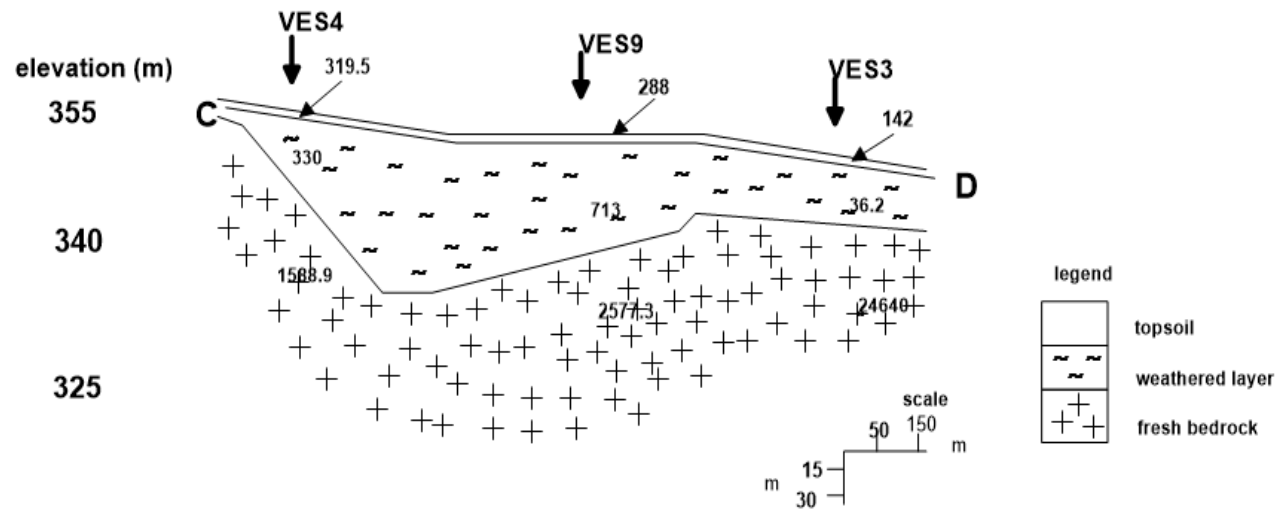

Fig. 9: Geoelectric Section Along Trraverse 2.

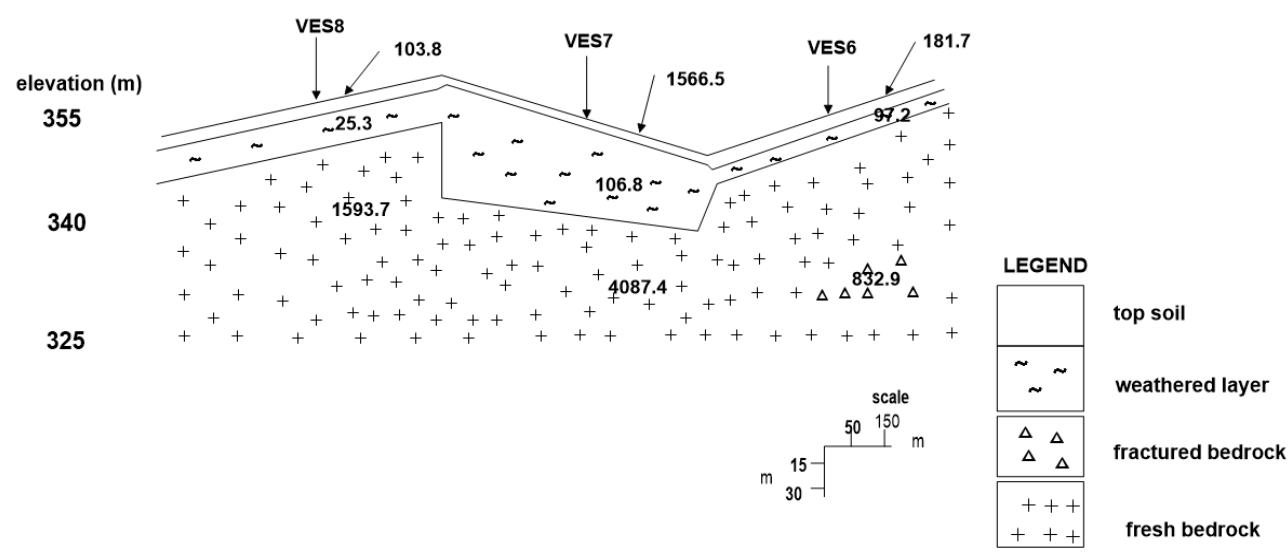

Fig. 10: Geoelectric Section Along Traverse 3. 


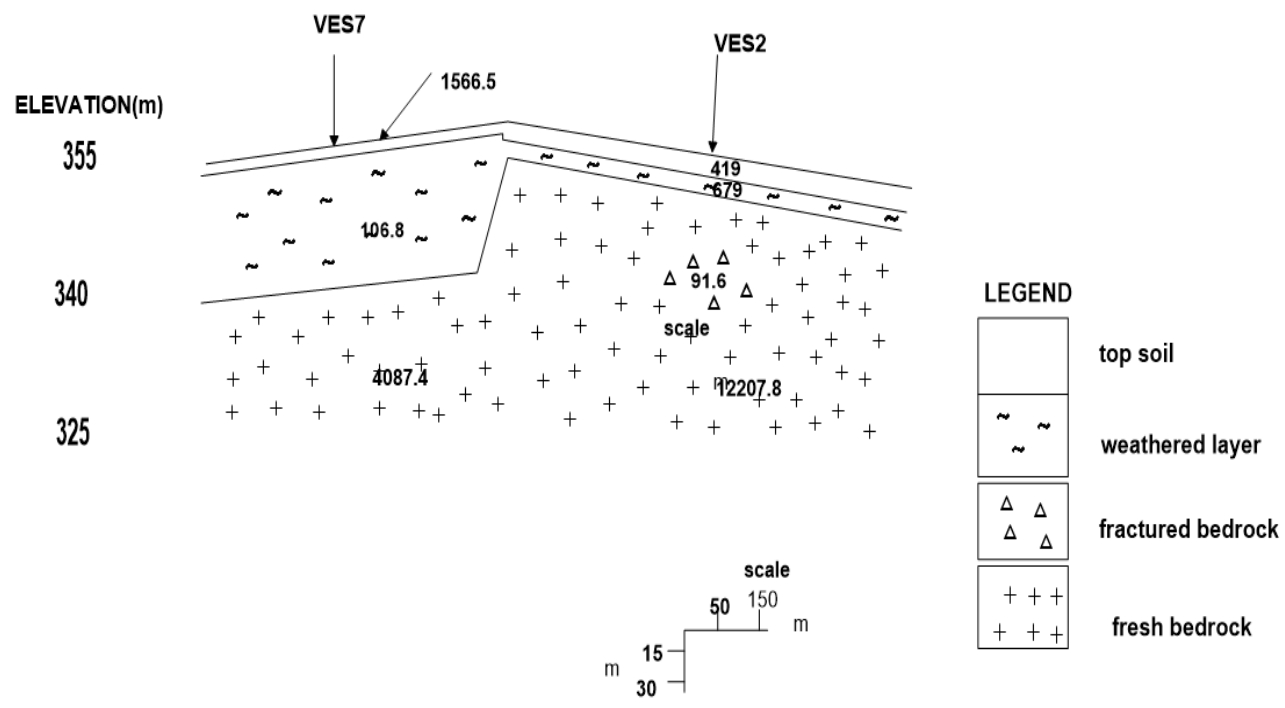

Fig. 11: Geoelectric Section Along Traverse 4.

\subsection{Resistivity and thickness map of weathered layer}

In between the topsoil or lateritic layer and fresh or fractured bedrock is the weathered defined in this study as materials constituting the regolith. The map was generated in order to observe how the weathered basement (aquifer zone) varied from one place to another. Fig 13 shows the weathered layer thickness map within the study area. It shows that the weathered layer thickness of the study area varies from $1-14.5 \mathrm{~m}$ but less than $10 \mathrm{~m}$, which indicates a thin weathered layer across the study area. The areas with highest thickness on the map indicates groundwater potential zone. An aquifer resistivity map was generated from the interpreted VES data results in order to have an insight to the groundwater development of the study area. The aquifer resistivity value of each VES station was plotted and contoured as shown in figure 12.The map was generated in order to differentiate and distinguish low water-bearing zones and high water-bearing weathered layer zone and to find out whether or not the degree of saturation/weathering varies from one point to another in the study area. The resistivity value in the study area ranges from $50-900 \Omega \mathrm{m}$ as shown in figure 12 . This shows low clay composition and also reveals a saturated formation which is capable of water accumulation and transmission. The weathered layer constitutes the main aquifer unit in the area.

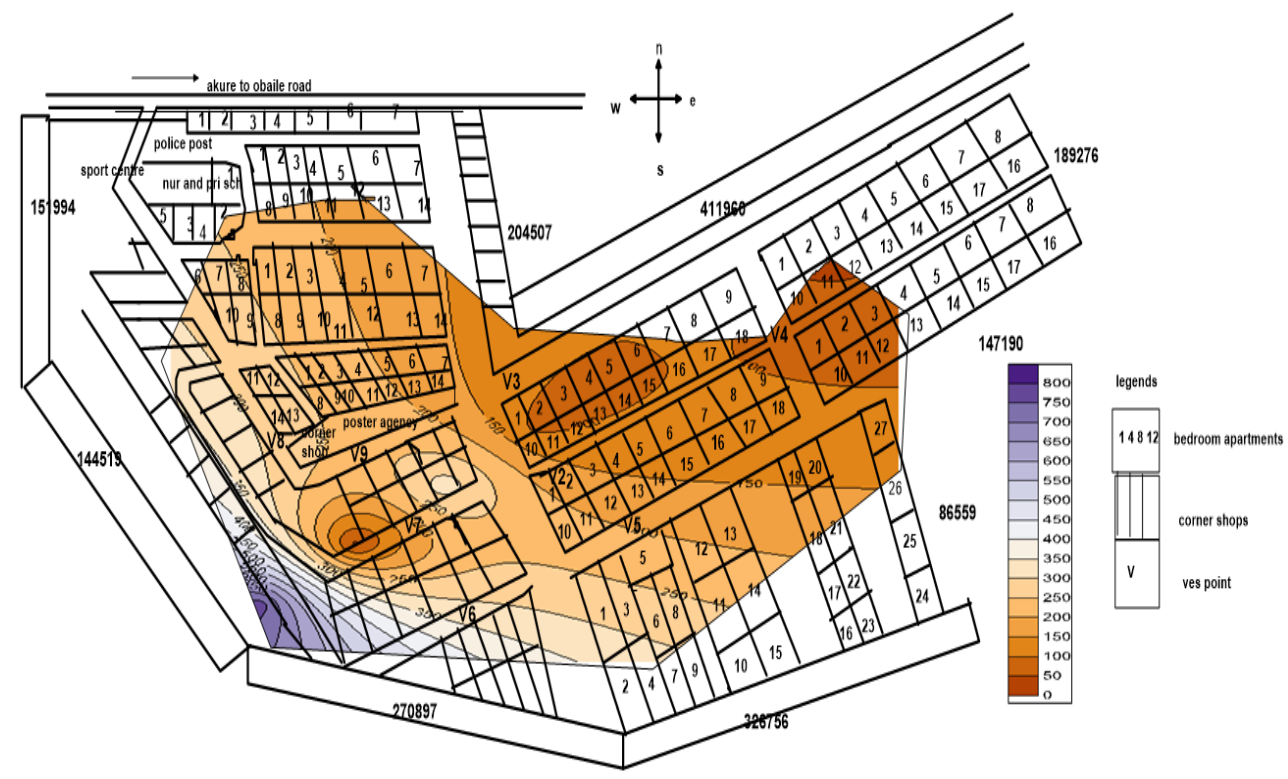

Fig. 12: Weathered Layer Map. 


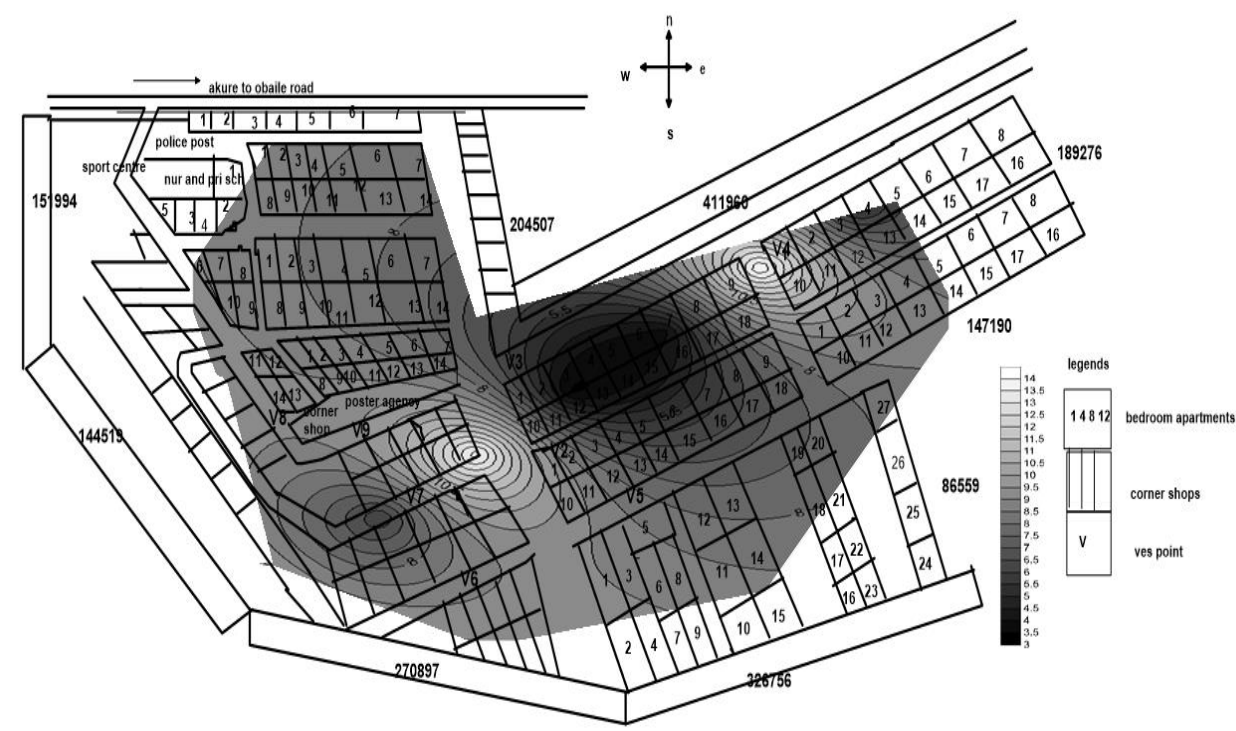

Fig. 13: Weathered Layer Thickness Map.

\subsection{Overburden thickness map}

The overburden thickness map was produced by plotting and contouring interpreted depth to bedrock beneath all the VES stations. This was done in order to have an insight into the general view of the aquifer geometry of the study area. The overburden is generally assumed to consist of the lateritic horizon, topsoil, and the clay/weathered rock. Figure 14 shows the depth to the top of the fresh bedrock beneath the VES stations. The depth to bedrock ranges from 3-16m.The overburden thickness map reveals areas of relatively thick overburden (generally greater than $13 \mathrm{~m}$ ) and areas of relatively thin overburden (generally less than $10 \mathrm{~m}$ ). Studies in similar basement complex terrain [8][9] have identified zones with thick overburden cover are potential zone for groundwater while areas with overburden thickness of greater than $13 \mathrm{~m}$ are priority areas for groundwater development.

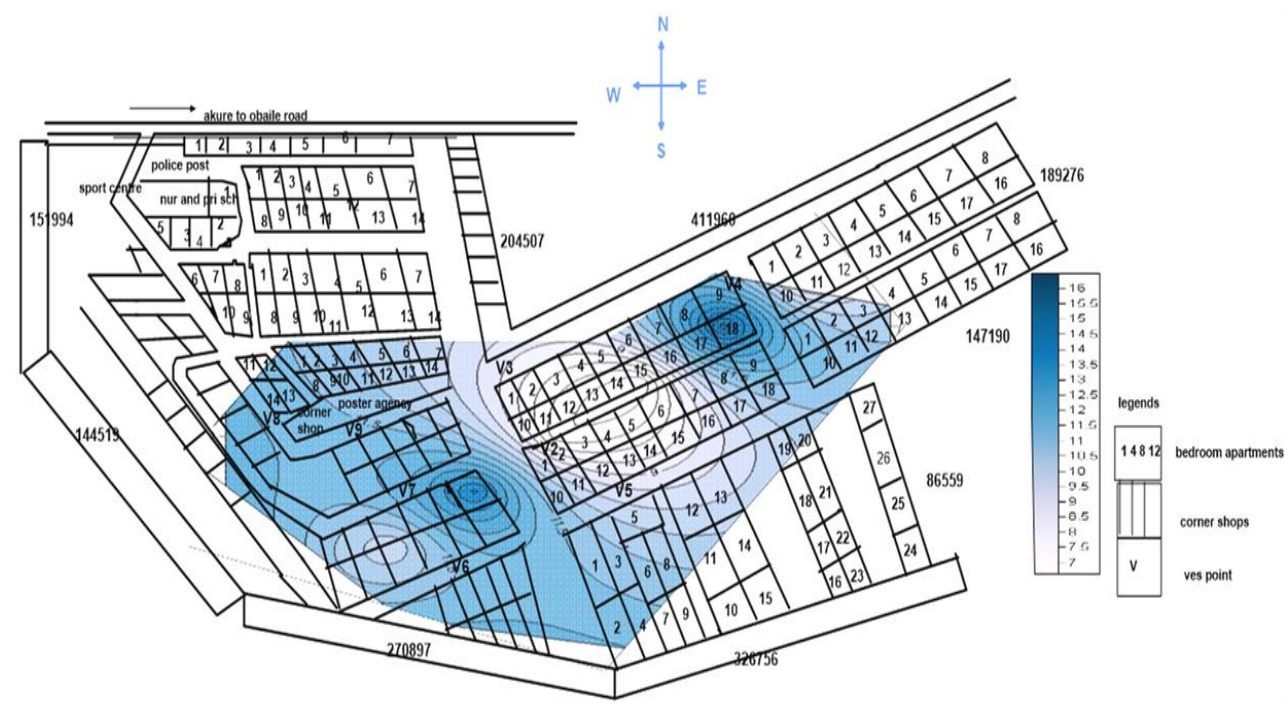

Fig. 14: Overburden Thickness Map.

\subsection{Bedrock relief map}

The bedrock relief map is a contoured map of the bedrock elevation beneath all the VES stations. The elevations of the bedrock were obtained by removing the thickness of the over burden cover from the elevation of the surface of each VES stations. The bedrock relief map produced for the locations reveals the topography of the bedrock across the surveyed area. Groundwater prospects areas can be seen vividly from the Bedrock relief map. Basement depressions areas on the map serve as groundwater collecting trough which is the best zones for Groundwater prospect. Bedrock relief has been used by [10][11] to investigate into Groundwater prospects at Ile-Ife Southwest, Akure Southwest, Kaduna North central, and Gussau Northwest part of Nigeria respectively. Procedures used by these authors have been adopted in this study in order to get the potential areas for Groundwater development at Sunshine Garden Estate Southwest Nigeria. The depression Zones are noted for thin overburden cover. This Depression serves as Groundwater collecting troughs for water Displaced from the ridges. These features delineated and identified D1-D3 in figure 15 often constitutes priority areas for Groundwater Development in basement setting. 


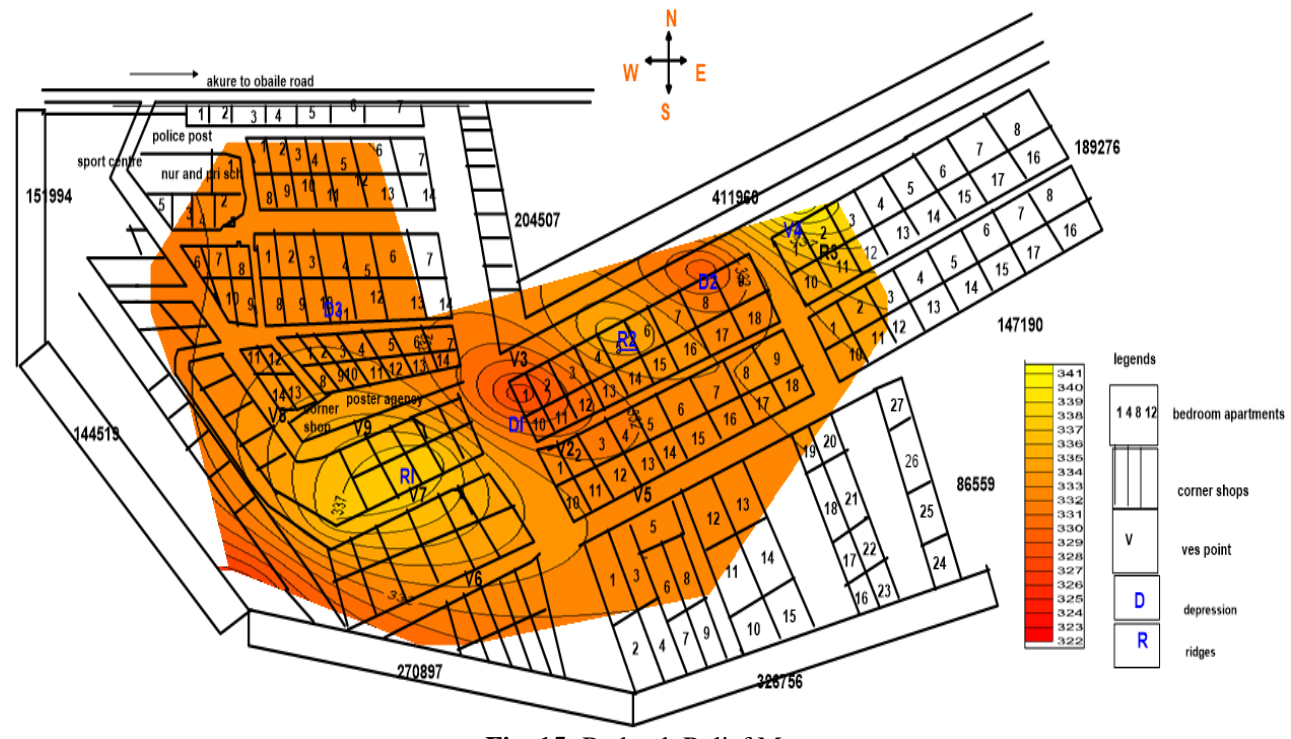

Fig. 15: Bedrock Relief Map.

\subsection{Groundwater potential map}

Figure 16 shows the groundwater potential map of the study area. This map was generated in order to draw the final conclusion from the evaluated maps. The evaluation of the study area is based on the resistivity of the weathered layer and the thickness of the overburden, since the nature of the thickness and weathered layer are parameters in the evaluation of groundwater potential of a basement complex terrain [8]. The horizon is also referred to as a significant water bearing zone most especially if significantly thick and the resistivity parameters suggest saturated conditions [12]. The groundwater potential of the study area was zoned into low, medium and high potentials. Zones where the overburden thickness (which constitutes the main aquifer unit) is greater than $13 \mathrm{~m}$ and of low clay composition (average resistivity value between $200-400 \Omega \mathrm{m}$ ) are considered zones of high groundwater potential. Area where the thickness of the aquifer ranges from 11-13m with less clay composition are considered to have medium groundwater potential and the areas where the thickness of the aquifer is less than $11 \mathrm{~m}$ are considered to have a low groundwater potential.

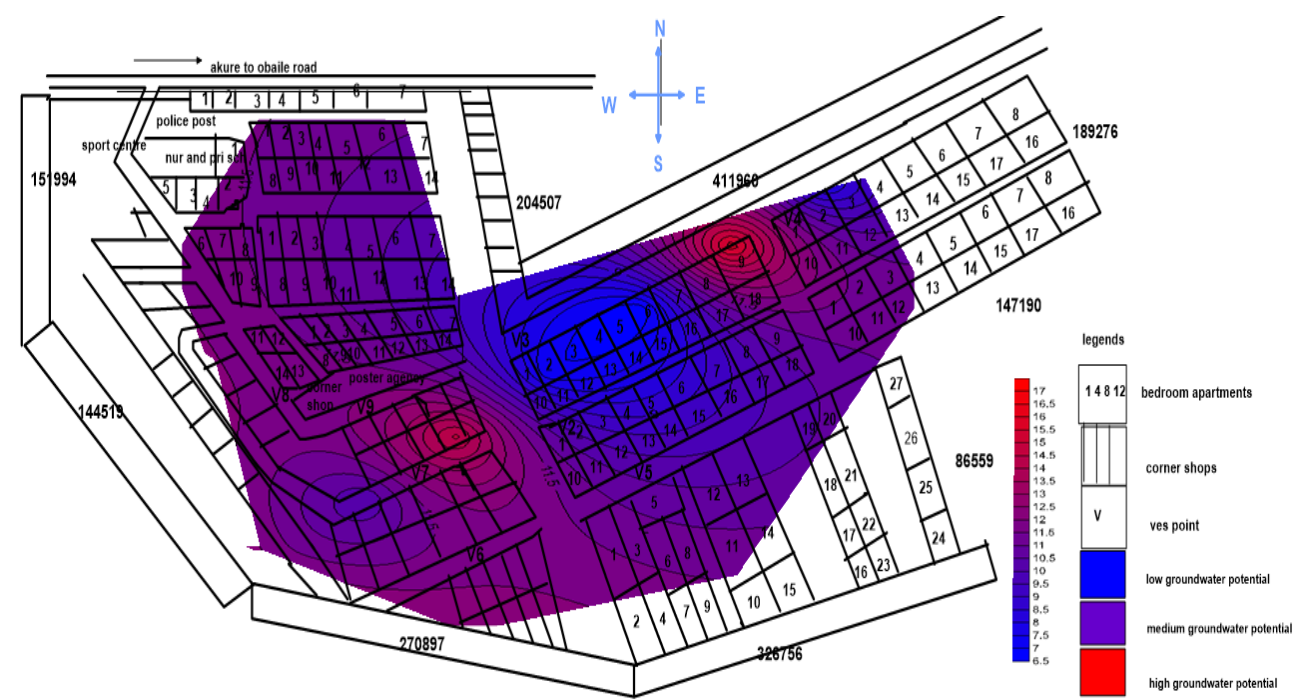

Fig. 16: Groundwater Potential Map of Sunshine Estate Oba-Ile Akure.

\section{Conclusion}

The Vertical Electrical Resistivity surveys in the Sunshine Garden Estate have contributed to a better understanding of the basement complex of Southwestern Nigeria. Based on the results obtained from this survey, it can be concluded that the electrical resistivity methods are efficient and significant tools for borehole sitting in groundwater exploration. In this study, data from the survey which are presented as geoelectric sections and maps has provided information on the subsurface disposition and hydro-geologic framework of major aquifer units in the study area. The groundwater potential of the study area was zoned into low, medium and high potentials. Zones where the overburden thickness is greater than $13 \mathrm{~m}$ and of low clay composition are considered zones of high groundwater potential.

\section{References}

[1] Miller R (2006). Hydrogeophysics: Introduction to this special section. The Leading Edge. P. 713. https://doi.org/10.1190/1.2210053.

[2] Billings MP (1972). Structural Geology (3rd Edition) 33-34 Prentice-Hall Englewood Cliffr. NJ.

[3] Maliek SB, Bhattacharya DC, Nag SK (1973). Behavior of fractures in hard rocks - a study by surface geology and radial VES methods. Geoexploration 21:529-556. 
[4] Olayinka AI, Olorunfemi MO (1992). Determination of geoelectrical characteristics in Okene area and implication for Borehole sitting. J. Mining Geol. 28(2):403-412.

[5] Omosuyi, G.O., Ojo J.S. and Enikanselu, P.A. 2003. "Geophysical Investigation for Groundwater around Obanla - Obakekere in Akure Area within the Basement complex of South-Western Nigeria". Journal of Mining and Geology. 39(2):109 - 116. https://doi.org/10.4314/jmg.v39i2.18799.

[6] Rahaman, M. A. 1988. Recent advances in the study of Basement Complex of Nigeria, Geological Survey of Nigeria,

[7] Worshington, P.R. 1977: "Geophysical Investigations of Groundwater Resources in the Kalahari Basin". Geophysics. 42(4):838-849 https://doi.org/10.1190/1.1440751.

[8] Bala, A.E. and Ike, E.C. 2001. "The Aquifer of the Crystalline Basement Rocks in Gusau Area, North-Western Nigeria". Journal of Mining and Geology. 37(2): $177-184$.

[9] Omosuyi, G.O., Ojo J.S. and Enikanselu, P.A. 2003. "Geophysical Investigation for Groundwater around Obanla - Obakekere in Akure Area within the Basement complex of South-Western Nigeria". Journal of Mining and Geology. 39(2):109 - 116. https://doi.org/10.4314/jmg.v39i2.18799.

[10] Okhue, E. T. \& Olorunfemi, M. O. (1991): Electrical resistivity investigation of a typical Basement Complex area. The Obafemi Awolowo University campus case study. J. Mining Geol., Vol. 2, (27), 63-69.

[11] Dan-Hassan, M. A. \& Olorunfemi, M. O. (1999): Hydrogeophysical investigation of a basement terrain in the north central part of Kaduna State, Nigeria. Journal of Mining and Geology, Vol. 2, (35), 189-206.

[12] Shemang, E. M. 1990. Electrical depth sounding at selected well sites within the Kubari river basin, Zaria, Nigeria. Unpublished M.Sc. Thesis A. B. U. Zaria, pp108. 